\title{
NEGAÇÃO E FOCALIZAÇÃO EM SATERÉ-MAWÉ
}

\section{NEGATION AND FOCALIZATION CONSTRUCTIONS IN SATERÉ-MAWÉ}

\author{
Dulce do Carmo Franceschini \\ Universidade Federal Fronteira Sul, UFFS, Chapecó, SC, Brasil \\ Laboratório de Línguas e Literaturas Indígenas, LALLI/Universidade de Brasília \\ Denize de Souza Carneiro \\ Universidade Federal de Uberlândia, UFU, Uberlândia, MG, Brasil
}

\begin{abstract}
Resumo: Pretende-se, neste artigo, apresentar uma análise do funcionamento da negaçáo em Sateré-Mawé e sua relação com processos enunciativos que têm por objetivo focalizar diferentes termos do enunciado. Esta análise se fundamenta, principalmente, em pressupostos teóricos do Funcionalismo-Tipológico desenvolvidos por teóricos franceses. O corpus empregado para esta análise é constituído de enunciados retirados de textos escritos por professores indígenas e publicados sob a forma de livros de leitura para uso escolar; e de textos orais coletados por nós em situaçóes reais de comunicação.
\end{abstract}

Palavras-chave: Língua Sateré-Mawé; negação; focalização.

Abstract: In this essay, we attempt to present an analysis of the negation mechanisms in Sateré-Mawé and its relation with enunciative processes whose purpose is to focus different elements of the sentence. This analysis is based mainly on the theoretical presuppositions of the Typological-Functionalism, which were developed by French theorists. Its corpus is constituted by sentences obtained through texts written by indigenous teachers and published as reading books for classroom use and by oral texts collected in real situations of communication.

Keywords: Sateré-Mawé language; negation; focalization constructions.

\section{Introduçáo}

A Língua Sateré-Mawé foi classificada por Rodrigues (2002) como membro único da Família Linguística Mawé, pertencente ao Tronco Tupi. O povo sateré-mawé, cerca de 12.000 pessoas (segundo comunicação oral da Secretaria de Saúde Indígena de Parintins-AM, em 2014), vive na região do Baixo Amazonas, localizada no sudeste do Estado do Amazonas, na fronteira com o Estado do Pará, no Brasil. O território pertencente aos sateré-mawé (Terra Indígena Andirá-Marau), já demarcado e homologado, compreende 788.528 mil hectares e se subdivide em três sub-regióes administrativas no Estado do Amazonas: a dos rios Marau e Urupadi, município de Maués; a 
do rio Andirá, município de Barreirinha e a do rio Waikurapá, município de Parintins. Alguns membros do grupo vivem no município de Borba, também no Estado do Amazonas, no território dos Mundurukú, onde possuem 01 (uma) comunidade, Kuata-Laranjal; esses sateré-mawé viviam no rio Andirá e foram transferidos, em meados dos anos setenta, para o território mundurukú pela Fundação Nacional dos Índios (FUNAI) em consequência de brigas internas. Nossa pesquisa de campo foi realizada em comunidades indígenas situadas às margens do rio Andirá, onde desenvolvemos, desde o ano 2.000 , projetos de pesquisa-ação na área educacional com a finalidade de revitalizar a língua e as práticas tradicionais indígenas.

A seguir, apresentamos o quadro teórico que embasa a nossa análise, seguido da análise do funcionamento da negaçáa e sua relação com processos de focalização em Sateré-Mawé.

\title{
Negaçáo
}

Dentre os diferentes enfoques sob os quais a negação pode ser tratada, muitos dos estudos nas diferentes línguas do mundo têm sido feitos a partir de uma definição lógica da negação. Nesta perspectiva, a negação é definida como:

\begin{abstract}
[...] un opérateur propositionnel, c'est-à-dire qu'elle opère sur une proposition $p$, et forme avec cette proposition $p$ une nouvelle proposition notée par $\bar{p}$ ou $\sim p$, c'est-à-dire non- $p$, dont la valeur logique (ou valeur de vérité) est l'inverse de celle de $p$ : si $p$ est vrai, $\bar{p}$ est faux, et si $p$ est faux, $\bar{p}$ est vrai $^{1}$ (TOURATIER, 2007, p. 13, grifo do autor).
\end{abstract}

A negação é considerada, portanto, a partir do ponto de vista da lógica, como um operador que inverte as condiçóes de verdade do conteúdo proposicional ao qual se aplica. Quando esse operador é aplicado a um conteúdo proposicional que é objeto de uma asserção, ele se manifesta por uma inversão sistemática do valor de verdade dessa asserção (CREISSELS, 2006, p. 129).

Segundo Creissels (2006, p. 130), embora o emprego de asserçóes negativas tenha fortes implicaçóes discursivas, a descrição da negação

\footnotetext{
${ }^{1}$ Tradução nossa: "um operador proposicional, quer dizer que ela [a negação] opera sobre uma proposição $p$, e forma com essa proposição $p$ uma nova proposição cuja notação é $p$ ou $\sim p$, isto é, não- $p$, cujo o valor lógico (ou valor de verdade) é o inverso daquele de $p$ : se $p$ é verdadeiro, $\not p$ é falso e se $p$ é falso, $\not$ é verdadeiro" .
} 
de uma língua deve ser feita a partir de sua definiçâao lógica, o que não implica negar os diferentes efeitos de sentido produzidos pela negação nas diferentes línguas do mundo. Esse autor considera que quaisquer que sejam as especificidades da asserção negativa como ato de linguagem distinto da asserção afirmativa, e quaisquer que sejam os efeitos de sentido produzidos pela combinação da negação e de modalidades enunciativas outras que a asserção, trata-se aí da exploração enunciativa de uma noção (a negação), cuja definição provém da lógica, isto é, do estudo das condiçóes de verdade dos conteúdos proposicionais, e não de uma teoria da enunciação.

Sendo assim, para Creissels (2006, p. 137-138), a "negação de frase" é um mecanismo morfossintático que, aplicado a uma frase assertiva, resulta em uma frase que se distingue da primeira, tanto pela inversão do valor de verdade, como por um conjunto de propriedades sintáticas que não estão presentes em frases que não apresentam nenhuma espécie de negação.

Esse autor considera frase negativa todo enunciado que apresenta uma negação, podendo essa ter uma incidência variável, náo limitada ao grupo verbal. Sendo a negação ordenada e determinada por cada sistema linguístico em particular, as variaçôes da incidência da negação podem ser condicionadas tanto pela natureza morfossintática dos indicadores de negação (por exemplo, a mobilidade de partículas negativas), quanto pela forma como cada língua organiza a focalização, conforme explica Creissels:

En effet, focaliser un terme d'une phrase assertive, c'est marquer une restriction sur la portée de l'assertion. Il n'est donc pas étonnant que l'explicitation de la portée de la négation puisse faire appel, non seulement à des constructions clivées [...], mais de manière plus générale aux procédés utilisés dans les phrases assertives positives pour marquer une focalisation, notamment l'intonation (CREISSELS, 2006, p.133-137)2.

Focalizar um termo da frase assertiva é, conforme esse autor, marcar uma restriçáo sobre a incidência da asserção; não seria, portanto, surpreendente que, para a explicitaçáo da incidência da negação, se recorra a construçóes clivadas, mas também - e com mais frequência - a procedimentos empregados nas frases assertivas afirmativas para marcar uma focalização, especialmente a entonação.

\footnotetext{
${ }^{2}$ Tradução nossa: De fato, focalizar um termo de uma frase assertiva é marcar uma restrição sobre a incidência da asserçâo. Não é, entấo, surpreendente que a explicitação da incidência da negação possa recorrer, não somente à construçốes clivadas [...], mas de maneira mais geral aos procedimentos utilizados nas frases assertivas positivas para marcar uma focalizaçăo, particularmente a entonação.
} 
Estratégias de negação podem, portanto, em determinadas línguas, dentre essas a Língua Sateré-Mawé, implicar no uso de estratégias de focalização, tais como o emprego de construçóes clivadas, a posição do termo ou a entonação.

\section{Focalizaçáo}

A focalização, assim como a topicalização, são definidas por Creissels (2006, p. 109-116) como "opérations ayant pour effet d'expliciter la structure discursive de la phrase, quels que soient les procédés formels mis en œuvre" . Sendo assim, focalização e topicalização são estratégias empregadas para assinalar explicitamente no enunciado o foco e o(s) tópico(s).

O tópico é definido por esse autor como "um elemento do enunciado a partir do qual o enunciador desenvolve um comentário"; já o foco como um elemento que "é apresentado como particularmente carregado de um valor informacional elevado" 4 .

A escolha do tópico e do foco em um enunciado, para Creissels (2006) e Hagège (1982) $)^{5}$, está subordinada ao contexto enunciativo e à intenção comunicativa do enunciador, pois o já conhecido e o novo "não são conceitos absolutos, cabe ao falante analisar o interlocutor e a situação para decidir o que será tema e o que será rema. Isso explica por que uma mesma oração pode ter diferentes articulaçôes" (CASTILHO apud ILARI, 1992). Segundo Creissels (2006), as línguas podem apresentar enunciados sem tópico, mas não sem foco e também podem topicalizar vários termos em um mesmo enunciado (encadeamento de tópicos), porém náo é possível focalizar dois termos de um mesmo enunciado.

A relação entre as funções discursivas tópico e $f o c o^{6}$ e as funções sintáticas são reguladas pelas línguas de maneira muito variável (CREISSELS, 2006, p. 112). Assim sendo, há línguas nas quais os sistemas permitem (mas não totalmente) que os papéis sintáticos coincidam com os discursivos

\footnotetext{
${ }^{3}$ Tradução nossa: operaçôes que têm por objetivo explicitar a estrutura discursiva da frase, quaisquer que sejam os procedimentos formais empregados.

${ }^{4}$ Tradução nossa.

${ }^{5}$ Hagège emprega os termos tema e rema com o mesmo valor que os termos tópico e foco são empregados por Creissels.

${ }^{6}$ As funçōes tópico e foco fazem parte da análise do nível discursivo (CREISSELS, 2006) ou enunciativo-hierárquico (HAGËGE, 1982, p. 32) do enunciado; segundo esses autores, além da análise desse nível, um enunciado deve também ser analisado no nível morfossintático (funçôes sintáticas) e no nível semântico-referencial (papéis semânticos).
} 
(sujeito=tópico e predicado=foco), mas há outras onde não ocorre nenhuma equivalência, pois o sistema linguístico faz distinção entre essas duas noçôes, como, por exemplo, o húngaro e o basco.

Segundo Creissels (2006, p. 109), o sistema de uma língua permite construir frases diferentes a partir de um mesmo conjunto de constituintes nominais e de um mesmo verbo em função predicativa, com as mesmas implicaçôes referentes aos papéis semânticos atribuídos aos termos da construção do verbo, porém apresentando discursivamente diferentes organizaçôes da informação, conforme ilustram os exemplos abaixo:
Tópico
//
Foco
(1) Virgínia
// comeu galinhada ontem.
Focalização
//
Tópico
(2) Foi galinhada
// que Virgínia comeu ontem.
(3) Foi ontem // que Virgínia comeu galinhada.

O exemplo (1) apresenta uma estrutura neutra do ponto de vista enunciativo-hierárquico, ou seja, sem topicalização e sem focalizaçáo; nesse exemplo, a função tópico é assumida pelo nome próprio "Virgínia”, e a função foco, pelos termos "comeu galinhada ontem". No entanto, de acordo com a intenção comunicativa do enunciador, outros termos dessa construção podem passar a funcionar como tópico ou foco mediante o emprego de estratégias de topicalização ou focalizaçâo. Nos exemplos (2) e (3), observase que o complemento de objeto direto "galinhada" e o circunstancial "ontem" sáo focalizados por meio do emprego de uma construçáo clivada ${ }^{7}$, o que implica em uma mudança de posição do termo focalizado (de pósverbal para pré-verbal).

Segundo Creissels (2006), quatro são as estratégias mais comuns empregadas nas línguas para topicalizar ou focalizar determinado termo (ou termos) do enunciado, a saber: 1) entonação; 2) adição de formas morfológicas; 3) ordem das palavras (posição); 4) combinação da entonação e ordem das palavras elou adição de formas morfológicas.

\footnotetext{
${ }^{7}$ Tradução nossa: Chama-se estrutura clivada uma construção na qual a unidade posta em valor é inserida entre dois monemas especializados (frequentemente um auxiliar de predicaçáo e uma "RELATIVA" (COSTAOUEC; GUÉRIN, 2007, p. 243, grifo dos autores), o que se verifica em Português.
} 
Quanto à focalização, Creissels (2006) distingue a focalização simples (ou informativa) da focalização contrastiva. $\mathrm{Na}$ focalização simples, o foco chama a atenção para uma informação julgada importante. Essa noção está estreitamente ligada à noção de interrogação, sendo, então, foco a informação que falta em uma interrogação parcial, ou, na asserção, o que é apresentado como a informação que preenche uma lacuna.

Por sua vez, a focalização contrastiva abrange vários tipos de estruturas comunicativas, as quais implicam um contraste entre a informaçáo em foco e uma informação alternativa, que pode aparecer explicitamente ou pressuposta, conforme apresentamos a seguir (CREISSELS, 2006, p. 121):

\section{1) Focalização de rejeição}

A: - João foi ao teatro com a Ana.

B: - Nấo, não foi com a Ana que ele foi ao teatro.

2) Focalização de substituição

A: - João foi ao teatro com a Ana.

B: - Não, foi com a Carla que ele foi ao teatro.

Creissels (2006) observa que a focalização de substituição aparece frequentemente combinada, na mesma frase, com uma focalizaçáo de rejeição, conforme exemplo abaixo:

A: - João foi ao teatro com a Ana.

B: - Não, não foi com a Ana que ele foi ao teatro, foi com a Carla.

3) Focalização de expansão:

A: - João foi ao teatro com a Ana.

B: - Não só foi ao teatro com a Ana, ele também a levou em casa.

4) Focalização de restrição

A: - João saiu com a Ana e a Carla.

B: - Não, ele saiu somente com a Carla.

5) Focalização de seleção

A: - Eu me pergunto se João saiu com a Ana ou com a Carla.

B: - Posso te dizer que foi com a Carla que ele saiu. 


\section{Negaçáo e focalizaçáo}

Segundo Creissels (2010, p.18), a negação - assim como a interrogação - vem sendo considerada por muitos estudiosos como inerentemente focal. Para esse autor, no entanto, essa questão não é tão simples quanto parece, ou seja, o papel da negação, no nível enunciativo-hierárquico (ou discursivo), apresenta-se mais complexo do que muitas vezes é apresentado.

A partir da análise da focalização em enunciados afirmativos e negativos em húngaro, basco e armênio oriental, Creissels (2010) constatou que, nessas línguas, não é possível considerar a sintaxe da negação como previsível de maneira simples, atribuindo às marcas de negação um traço inerentemente focal, como propóem alguns estudiosos dessas línguas, pois, enquanto que a negação sempre ocorre imediatamente à esquerda do verbo, o mesmo não acontece com a focalizaçáo, conforme explica o autor:

Dans ces trois langues, la focalisation implique de manière plus ou moins contraignante l'adjonction à gauche du verbe [...]. Dit en d'autres termes, la notion de focalisation explique une partie de ce qui se passe dans ces langues immédiatement à gauche du verbe, mais une partie seulement. En outre, ces éléments qui dans les langues à focus préverbal tendent d'une manière ou d'une autre à se placer en position préverbale dans des phrases où il n'y a aucune focalisation n'ont pas un comportement homogène : ils doivent parfois céder la place à un terme focalisé, mais il peut aussi arriver qu'ils maintiennent leur position en cas de focalisation, le terme focalisé se plaçant alors immédiatement à gauche du bloc que l'élément en question constitue avec le verbe (ou avec l'auxiliaire). Or, c'est ce dernier type de comportement que nous avons observé pour les marqueurs de negation [...] (CREISSELS, 2010, p. 18-19) ${ }^{8}$.

Nesse trecho, Creissels (2010) conclui que a posição imediatamente pré-verbal nem sempre é ocupada pelo termo focalizado nessas línguas. Essa posição, em determinadas frases, é ocupada pelos marcadores de negação que formam um bloco com o verbo. Quanto ao termo focalizado, esse

\footnotetext{
${ }^{8}$ Tradução nossa: Nestas três línguas, a focalização implica de maneira mais ou menos obrigatória a adição à esquerda do verbo [...]. Dito em outros termos, a noçẫo de focalização explica uma parte do que se passa nestas línguas imediatamente à esquerda verbo, mas uma parte apenas. Além disso, esses elementos que nas línguas a foco pré-verbal tendem de uma maneira ou de outra a se colocar em posição pré-verbal em frases onde não tem nenhuma focalizaçáo não apresentam um comportamento homogêneo: eles devem às vezes dar lugar a um termo focalizado, mas pode também acontecer deles manterem sua posição em caso de focalização, o termo focalizado se colocando entáo imediatamente a esquerda do bloco que o elemento em questáo constitui com o verbo (ou com o auxiliar). Ora, é este último tipo de comportamento que nós observamos para os marcadores de negação[...].
} 
precederá o bloco NEG. + VERBO, o que leva esse autor a concluir que a negação, diferentemente da interrogação, nem sempre é focal nessas línguas.

Creissels (2010) volta a chamar a atenção nesse texto para a importância de não perder de vista a sintaxe da negação em um estudo sobre a organização da informação no enunciado, pois uma análise dos indicadores de negação no plano exclusivamente pragmático poderia levar a não compreensão da especificidade da sintaxe da negação, principalmente em línguas, nas quais esta pode ser deduzida facilmente da sintaxe da focalização.

Em Sateré-Mawé, ao contrário do húngaro, do basco e do armênio oriental, a negação é inerentemente focal. Sendo assim, enquanto nessas línguas os indicadores de negaçáo não incidem sempre sobre o termo focalizado, em Sateré-Mawé o foco dos enunciados negativos é o termo cuja negação incide sintaticamente, conforme apresentamos no tópico abaixo.

\section{Negação e focalização de constituintes em Sateré-Mawé}

Apresentamos, a seguir, uma análise da organização discursiva ou enunciativo-hierárquica do enunciado em Sateré-Mawé. Essa análise tem por objetivo compreender a organização informacional do enunciado, ou seja, a forma como o enunciador organiza em seu discurso a informação já conhecida (o tópico) e a informação nova (o foco). Geralmente, as línguas apresentam diferentes estratégias que permitem, de acordo com a intenção comunicativa do enunciador, focalizar diferentes termos do enunciado ou um enunciado como um todo.

Para compreendermos a focalização de enunciados negativos em Sateré-Mawé é necessário conhecermos primeiramente a organização de uma construção canônica, ou seja, sem focalização e sem topicalização, bem como as estratégias empregadas para focalizar constituintes em enunciados afirmativos. Isso é o que apresentamos a seguir.

\section{A construçáo canônica ou 'neutra'}

Em uma construção canônica em Sateré-Mawé, ou seja, 'neutra' do ponto de vista enunciativo-hierárquico, a ordem dos termos em um enunciado com verbo biactancial ${ }^{9}$ é a seguinte: primeiro actante + predicado $(=v e r b o)+$ segundo actante $+($ circunstante $)$; e em um enunciado uniactancial:

\footnotetext{
${ }^{9}$ Verbo que requer dois actantes (= verbos de valência 2$)$.
} 
actante único + predicado $(=v e r b o)+($ circunstante $)$. Assim sendo, o primeiro actante e o actante único ocorrem imediatamente antes do verbo; o segundo actante e o circunstante após o verbo, sendo que o segundo actante precede o circunstante, conforme mostram os exemplos a seguir:

a) Ordem dos termos em enunciado biactancial canônico:
(1) kurum
$\varnothing \quad-$ tu $\quad$ - Pu
pira
ja?atpo
'menino'
$3 \mathrm{Ag}^{10} .+$ At. I + 'comer' 'peixe' 'ontem'
primeiro actante + predicado + segundo actante + circunstante "O menino $/ /{ }^{11}$ comeu peixe ontem."

b) Ordem dos termos em enunciado uniactancial canônico:
(2) kurum
$\varnothing$ - to - ket
'menino'
$3 \mathrm{Ag}+$ Méd.I + 'dormir'
actante único
predicado
"O menino // dorme (está dormindo)."

Do ponto de vista enunciativo-hierárquico, o primeiro actante ou o actante único funcionam como tópico em um enunciado canônico, e o predicado seguido do segundo actante e do circunstante, quando esses últimos estiverem presentes no enunciado, como foco.

O primeiro actante ou o actante único é o actante indiciado no verbo, ou seja, que se encontra prefixado ao verbo. Em construçóes com verbos de processo ativos (biactanciais), o tópico será o primeiro actante. Em construçôes com verbos de processo médios e verbos de estado, o tópico será o actante único. O foco, por sua vez, é o predicado e os constituintes que assumirem a função sintática de segundo actante e/ou de circunstante, conforme mostram os exemplos a seguir.

\footnotetext{
${ }^{10}$ Abreviações empregadas nos exemplos: Ag.= prefixo pessoal agentivo; In. = prefixo pessoal inativo; At.I e At.II= índice da voz ativa I ou ativa II; Méd.I e Méd.II = índice da voz média I ou II; Atr.I e Atr.II = índice da voz atributiva I ou II; Inv. = índice da voz inversa; 1 Excl. $=1^{\mathrm{a}}$ pessoa exclusiva; 1 Incl. = $1^{\text {a }}$ pessoa inclusiva; posp. = posposiçấo.

${ }^{11}$ A barra dupla (//) marca o enunciado bipartido em tópico-foco ou foco-tópico.
} 
(a) Exemplo com verbo ativo:
(3) iasmim
/I
$\varnothing-\mathrm{ti}-\mathrm{hi} \mathrm{iu}$
wasa?i
'Yasmim'
3Ag. + At.I + 'beber' 'açaî'
"Yasmim // bebeu açaí."

Nesse enunciado, que é neutro do ponto de vista enunciativohierárquico, o tópico é Iasmim e o foco tibi?u wasa?i ("bebeu açaî"). Sintaticamente, o tópico (Iasmim) assume a função de primeiro actante e o papel semântico de agente do processo expresso pelo verbo; já o foco é constituído pelo predicado (tibi? $\boldsymbol{u}$ ) e pelo segundo actante (wasa? $\boldsymbol{i}$ ), o qual assume o papel semântico de paciente no enunciado.

b) Exemplo com verbo médio:

(4) uito // a - re - to koiti?i
'eu' $1 \mathrm{Ag} .+$ Md.I + 'ir' 'hoje'
"Eu // vou (viajo) hoje."

Nesse enunciado, o papel discursivo de tópico é assumido por uito ("eu"), e o foco, por areto koiti?i ("vou hoje"). Sintaticamente, o tópico funciona como actante único e assume o papel semântico de agente do processo; já o foco é constituído pelo predicado areto e pelo circunstante indicador de tempo koiti? (hoje).

(c) Exemplos com verbos de estado:
(5) kurum $\varnothing-\mathrm{i}-\mathrm{kahu}$
'menino' 3In. + Atr.I + 'ser bonito'
"O menino // é bonito."

Em (5), o tópico é kurum ("menino"), e o foco, ikahu ("é bonito"). Sintaticamente, o tópico assume a função de actante único e o papel semântico de atributivo; já o foco ikabu assume a função de predicado que atribui uma qualidade/característica ao participante indiciado no verbo, ou seja, ao actante único. 


\section{Focalizaçáo de constituintes em enunciados afirmativos}

Para compreendermos quais os mecanismos empregados para focalizar constituintes em enunciados negativos da Língua Sateré-Mawé, fez-se necessário analisar, primeiramente, como ocorre a focalização em enunciados que não comportam negaçáo.

Verificou-se que, em enunciados afirmativos, empregam-se as seguintes estratégias para focalizar um constituinte: (a) colocação do termo focalizado em início de frase, ou antes do verbo, aliada à (b) uma entonação ascendente e, frequentemente, (c) à adição, após o termo focalizado, dos morfemas: $\boldsymbol{n} \boldsymbol{e} \boldsymbol{k} \overline{\boldsymbol{e}}$ ou $\boldsymbol{t} \boldsymbol{i}^{\mathbf{1 2}}[\sim \boldsymbol{n i} \sim \boldsymbol{r i}]^{13}$, sendo este último seguido, na maioria das vezes, de uma das diferentes partículas enunciativas (ran, rat, $k \boldsymbol{k} \boldsymbol{e}$ ) ou de morfemas indicadores de aspecto-modo-tempo (aru e ra?in), conforme apresentamos a seguir.

\subsection{Focalizaçáo do primeiro actante ou do actante único}

A focalização do termo na função de primeiro actante ou actante único é feita pela posição do termo focalizado em início de enunciado, aliada a uma entonação ascendente e, frequentemente, pelo emprego dos morfemas: $\boldsymbol{t} \boldsymbol{i}$ mais partícula enunciativa ou morfema indicador de aspectomodo-tempo; ou nekē, conforme mostram os exemplos abaixo:

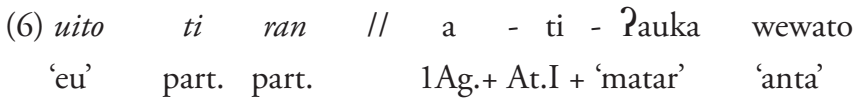

"Fui EU // que matei a anta."

Nesse exemplo, uito ("eu”) é focalizado, e a função de tópico é assumida por ati?auka wewato ("matei a anta"). Sintaticamente, o foco (uito) assume a função de primeiro actante e o papel semântico de agente; o tópico, por sua vez, é constituído pelo predicado ati?auka na voz ativa e pelo segundo actante wewato, que, semanticamente, é o paciente do

\footnotetext{
${ }^{12}$ A diferença entre o uso de uma ou outra partícula se deve a fatores pragmático-discursivos, que não serão discutidos neste texto.

${ }^{13}$ Essa variação na consoante inicial do morfema é determinada pelo contexto fônico em que ocorre, segundo a seguinte regra: após nasal a consoante inicial realiza-se como [n-]: [ni]; após vogal, $[\mathrm{k}]$ e $[\mathrm{p}]$ realiza-se como $[\mathrm{t}-]$ : [ti]; e após [t] como [r-]: [ri].
} 
processo expresso pelo verbo.
(7) eipe neke
// $\quad$ ewe - tu - ?u
pira
'vocês' part.
2Ag.pl. + At.I + 'comer' 'peixe'
"Foram VOCÊS // que comeram o peixe."

Em (7), eipe é focalizado, e a função de tópico é assumida por $\boldsymbol{e w e t u ? \boldsymbol { u }}$ pira ("comeram o peixe"). Sintaticamente, o foco (eipe) é o primeiro actante e assume o papel semântico de agente; já o tópico é constituído pelo predicado ewetu? $\boldsymbol{u}$ na voz ativa e pelo segundo actante pira no papel semântico de paciente.

Conforme se pode observar, a estratégia usada para focalizar o primeiro actante nesses enunciados é a posição em início de enunciado, a entonação ascendente e o emprego das partículas $\boldsymbol{t} \boldsymbol{i}+\boldsymbol{r a n}$, em (6), e $\boldsymbol{n} \boldsymbol{e} \boldsymbol{k} \overline{\boldsymbol{e}}$ em (7).

É importante destacar que, quando o actante focalizado faz referência à primeira e à segunda pessoa agentivas, conforme ilustram os exemplos anteriores, o verbo permanece na voz ativa; porém, quando o actante focalizado faz referência à terceira pessoa agentiva, ocorre uma mudança da orientaçáo do verbo que passa da voz ativa para a voz inversa. Da mesma forma, a função actancial do constituinte focalizado passa a funcionar como segundo actante no enunciado, já que não é mais esse participante que é indiciado no verbo, mas o participante que assume a função semântica de paciente. Para ilustrar essa mudança de construção, que é determinada pela sintaxe da focalizaçáo, vejamos os exemplos a seguir: sem focalização, exemplo (8), e com focalização, exemplo (9), do participante agentivo.

a) Enunciado sem focalizaçáo do participante agente $\mathbf{t}$ primeiro actante $\mathbf{t}$ voz ativa:

(8) waham

$$
\varnothing-\mathrm{tu}-\mathrm{Pu} \quad \overrightarrow{\mathrm{pira}}
$$

Waham 3Ag.sg. + At. + 'comer' peixe

"Waham comeu peixe."

b) Enunciado com focalizaçáo do participante agente ssegundo actante $\mathbf{1}$ voz inversa:

(9) waham ti ran $/ / \varnothing \quad-\quad \mathrm{i}-? \mathrm{u}$ pira waham part. part. 3In.sg. + Inv. + 'comer' peixe "Foi por Waham // que o peixe foi comido." 
No enunciado (9), a focalização do participante agente waham ocorre pelo emprego do morfema $\boldsymbol{t} \boldsymbol{i}$, seguido da partícula enunciativa ran. Observase que, para focalizar esse participante, é necessário mudar a orientação do verbo, que passa da voz ativa, marcada pelo prefixo - $\boldsymbol{t} \boldsymbol{u}$-, em (8), para a $v o z$ inversa, marcada pelo prefixo -i-, em (9).

Quanto ao prefixo de $3^{\text {a }}$ pessoa, embora apresente a mesma forma (Ø-) em (8) e (9), representa diferentes participantes: em (8), representa o participante agente, concordando, então, com o constituinte nominal waham; já em (9), representa o paciente e concorda, portanto, com o constituinte nominal pira. Essa mudança de orientação do verbo implica também uma mudança da funçấo actancial dos participantes: enquanto no exemplo (8), que apresenta uma construçáo na voz ativa, o primeiro actante é o participante agente, e o segundo actante, o paciente, em (9), que apresenta uma construção na voz inversa, o paciente é que assume a função de primeiro actante, e o agente focalizado funciona, sintaticamente, como segundo actante.

Já em enunciados uniactanciais com verbos médios, ou seja, que requerem apenas o emprego de um actante (actante único), a focalização da terceira pessoa não implica em uma mudança da construção verbal. Vejamos o exemplo a seguir:

(10) $m i r i$ ti aru // $\varnothing$ - to - to yo kape mojki?ite 'ele/ela' part. fut. 3Ag.+ Méd.I + 'ir/sg.' 'roça' posp. 'amanhä' 'Será ele/ela / que irá para a roça amanhá.

Em (10), o primeiro actante $\boldsymbol{m i} \boldsymbol{i} \boldsymbol{i}$ é focalizado, já o predicado toto e os circunstantes yo kape e moyki?ite funcionam como tópico.

No exemplo a seguir, que apresenta um verbo de estado, o actante único hirokat-ria (crianças) é focalizado, e o predicado hesi?at ("estão com fome”) funciona como tópico.

$$
\begin{aligned}
& \text { (11) hirokat - ria } \quad \text { ti } \\
& \text { 'criançă }+ \text { pl. } \\
& \text { "Saro as crianças // que estáo com fome." }
\end{aligned}
$$

Nesses exemplos, assim como nos precedentes, a estratégia empregada para focalizar o actante único é a posição em início de enunciado, a entonação ascendente e o emprego das partículas ti aru em (10), e $\boldsymbol{t} \boldsymbol{i}+\boldsymbol{r a t}$, em (11). 


\subsection{Focalizaçáo do segundo actante ou de um circunstante}

Para focalizar o segundo actante paciente ou um circunstante, empregam-se as mesmas estratégias que na focalização do primeiro actante, ou seja: (a) colocação do termo em posição inicial, o que implica no deslocamento do segundo actante ou do circunstante de sua posição canônica pós-verbal para a posição inicial; (b) entonação ascendente e (c) frequentemente, emprego de morfemas focalizadores.

Diferentemente da focalização do primeiro actante, a focalização do segundo actante ou de um circunstante, assim como a focalização do actante único, não implica em uma mudança da orientação do verbo, quaisquer que sejam os referentes do termo focalizado.

Nos exemplos (12) e (13) a seguir, ocorre a focalização do segundo actante; já nos exemplos (14) e (15) é um circunstante que é focalizado.

pira ti $\quad$ ran $/ /$ maria $\varnothing-$ tu - Pu
'peixe' part. part. 'Maria' 3Ag.sg. + At. I + 'comer'
"Foi peixe // que Maria comeu."
(13) tucunare neke // uito a - $\mathrm{t}$ - ekii 'tucunare' part. 'eu' 1 Ag. + At. I + 'puxei'
"Foi tucunaré // que eu puxei (pesquei)."

Os enunciados anteriores apresentam construçóes biactanciais com verbos de processo ativos: $\boldsymbol{t} \boldsymbol{u} \boldsymbol{\imath} \boldsymbol{u}$ (12) e ateki (13). Os constituintes pira e tucunaré, que funcionam como segundo actante, são os termos focalizados, portanto, apresentados pelo enunciador como os mais informacionais. A estratégia usada para focalizá-los foi a posição em início de enunciado, a entonação ascendente e o emprego das partículas $\boldsymbol{t} \boldsymbol{i}+\boldsymbol{r a n}$, em (12), e nekē em (13).

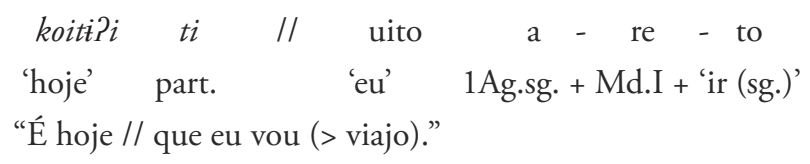


No enunciado (14), koiti? $\boldsymbol{i}$, que indica uma circunstância temporal, é focalizado; posiciona-se, então, em início de enunciado e é seguido pelo morfema $\boldsymbol{t} \boldsymbol{i}$, com o qual forma uma unidade fonológica com entonação ascendente.

\section{Focalizaçáo de constituintes em enunciados negativos do Sateré- Mawé}

Assim como nos enunciados afirmativos, a focalização de constituintes em um enunciado negativo é marcada pela posição inicial aliada a uma entonação ascendente do termo focalizado e das partículas enfáticas e enunciativas que o seguem.

Em enunciados que apresentam a negaçáo de um de seus constituintes actanciais ou circunstanciais, a posição do constituinte sobre o qual incide sintaticamente a negação é o início do enunciado ou pré-verbal; esse constituinte, assim como os constituintes focalizados em enunciados afirmativos, é seguido, frequentemente, de um dos morfemas focalizadores ( $\boldsymbol{n} \boldsymbol{e} \bar{k} \overline{\boldsymbol{e}}$ ou $\boldsymbol{t} \boldsymbol{i}$ ), formando com esse morfema uma unidade fonológica com entonaçáo ascendente. Sendo essas as principais estratégias usadas para focalizar constituintes em Sateré-Mawé, pode-se considerar que a negaçáo de um constituinte nessa língua implica em sua focalização, ou seja, que a negação é intrinsecamente focal.

\subsection{Negaçáo e focalização do primeiro actante ou actante único}

As mesmas estratégias empregadas para focalizar o primeiro actante ou o actante único em enunciados afirmativos são usadas para focalizá-los quando sobre os mesmos incide a negação. Vejamos os exemplos a seguir.

it uito $2 \boldsymbol{i}$ ti ran // a - ti - hìu sapo

NEG. 'eu' NEG. part. part. 1Ag. + At.I + 'beber' 'guaraná ralado' "Não fui eu // que bebi guaraná ralado."

(16) it uruto $2 \boldsymbol{i}$ neke // uru - i - pik oken - ipi NEG. 1Excl. NEG. part. 1Excl.Ag.+ At.I + 'quebrar' 'porta' "Não fomos nós // que quebramos a porta." 
(17) it en $\boldsymbol{i} \boldsymbol{i}$ neké // e - tu - nuך meikowat wa?ã NEG. 2sg. NEG. part. 2Ag. + At.I + 'fazer' 'esta' 'panela' "Não foi você // que fez esta panela."

Nesses exemplos, o constituinte que funciona como primeiro actante é focalizado: em (18), uito (eu); em (19), uruto (1Excl. 'nós') e, em (20), $\boldsymbol{e n}$ ('você'). Assim como nos enunciados afirmativos, a estratégia usada para focalizar foi a posição em início de enunciado, a entonação ascendente e o

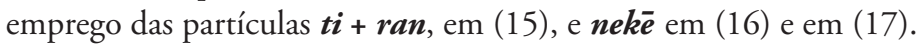

Nesses enunciados, o primeiro actante negado e focalizado faz referência à primeira pessoa, nos exemplos (15) e (16); e à segunda pessoa, no exemplo (17), sendo que essas assumem o papel semântico de agente no enunciado.

Observa-se que, nesses enunciados (15-17), o verbo apresenta uma orientação ativa. Conforme apresentado até então, o que determina o emprego de uma construçáo ativa ou inativa, quando o primeiro actante agentivo é focalizado, é a referência pessoal: quando esse actante faz referência à primeira ou à segunda pessoa, a construção verbal permanece ativa, assim como nas construçóes sem focalização do primeiro actante; já, se o primeiro actante agentivo fizer referência à terceira pessoa, sua negaçãofocalização implicará no emprego de uma construção verbal inativa e, consequentemente, na mudança de sua função actancial. $\mathrm{O}$ participante agente passa a funcionar como segundo actante, e náo mais como primeiro actante; o participante paciente passa a funcionar como primeiro actante, já que é ele que será indiciado no verbo. Como já apresentado, o mesmo ocorre na focalização do primeiro actante em enunciados afirmativos biactanciais. Vejamos os exemplos a seguir de enunciados sem e com focalização.

a) Enunciado afirmativo sem focalização do primeiro actante agentivo 1 voz ativa:

$$
\begin{aligned}
& \text { joão } \quad \varnothing-\mathbf{t i} \text { - Pauka moi } \\
& \text { 'João' } 3 \mathrm{Ag} .+ \text { At. + 'matar' cobra } \\
& \text { "João matou a cobra." }
\end{aligned}
$$

b) Enunciado afirmativo com focalização do agente $\mathbf{1}$ voz inversa:

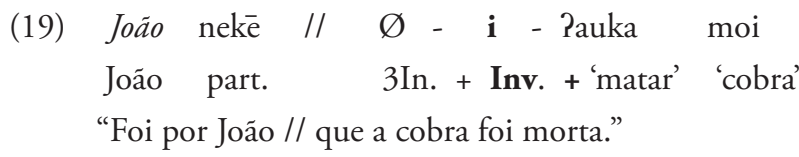


c) Enunciado negativo com focalização do agente $\mathbf{t}$ voz inversa:

(20) it João $2 \boldsymbol{i}$ neké // $\varnothing-\mathbf{i}$ - Pauka moi
NEG. João NEG. pt.enf. $\quad$ 3In. + Inv. + 'matar' 'cobra'
"Não foi por João // que a cobra foi morta."

Nos enunciados (19) e (20), o participante agente João é focalizado, já em (18) não há focalização. Nota-se que há uma mudança de voz ao focalizar esse participante, ou seja, a voz ativa, marcada pelo prefixo -ti-, em (18), passa à voz inversa, marcada pelo prefixo - $\boldsymbol{i}$-, em (19) e (20). Essa mudança de orientação do verbo (voz) também implica uma mudança da função actancial dos participantes, isto é: o participante agente deixa de ser o primeiro actante e passa a funcionar como segundo actante, e o participante paciente passa a funcionar como primeiro actante, já que é ele que se encontra indiciado no verbo. Quanto ao prefixo de $3^{\text {a }}$ pessoa, conforme já apresentado, embora apresente a mesma forma ( $\varnothing-)$ na construção ativa, exemplo (18), e na inversa, exemplos (19) e (20), este pertence a distintos paradigmas: em (18), faz referência ao paradigma de prefixos agentivos e, em (19) e (20), ao paradigma de prefixos inativos.

No entanto, em enunciados uniactanciais, os quais podem apresentar ou uma construção na voz inativa-atributiva ou média, a negação-focalização do actante único não implicará em uma mudança na orientação do verbo, conforme mostram os exemplos a seguir.

$\begin{array}{cllllll}\text { it } & \text { aito } & \text { 2i } & \text { // } & \text { mesūwat } & \text { ii } & \text { tote } \\ \text { NEG. } & \text { 1Incl. } & \text { NEG. } & & \text { pron. dem. } & \text { 'terra' } & \text { posp. }\end{array}$

wa - tu - we - rohik

1incl.Ag. + Méd.I + Refl. + 'comandar'

"Não somos nós // nesta terra que nos comandamos."

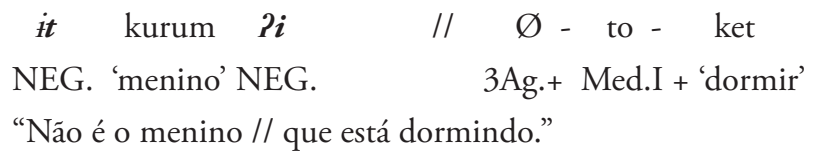

Nesses enunciados, éo actante único queénegadoe, consequentemente, focalizado: em (21), esse faz referência à primeira pessoa inclusiva aito ('nós') e, em (22), à terceira pessoa kurum ('menino'). 


\subsection{Negaçáo e focalizaçáo do segundo actante ou de um circunstante}

A negação e focalização de um constituinte que ocupa a função sintática de segundo actante e que desempenha o papel semântico de paciente ou de um circunstante é realizada mediante as mesmas estratégias empregadas para focalizá-lo em enunciados afirmativos, ou seja, pela mudança da sua posição canônica, que é depois do verbo, para a primeira posição do enunciado, aliada a uma entonação ascendente e, na maioria das vezes, pelo emprego de partículas enunciativas indicadoras de foco.

Vejamos os exemplos a seguir que apresentam a negação e focalização do segundo actante:

$$
\begin{aligned}
& \text { it wasa?i } \boldsymbol{i}_{\mathrm{i}} \text { neke // iasmim } \varnothing-\mathrm{ti}-\mathrm{hi} \text { ?u } \\
& \text { NEG. 'açaî' NEG. part. Yasmim 3Ag. + At.I + 'beber' } \\
& 2^{\circ} \text { actante } \quad 1^{\circ} \text { actante }
\end{aligned}
$$

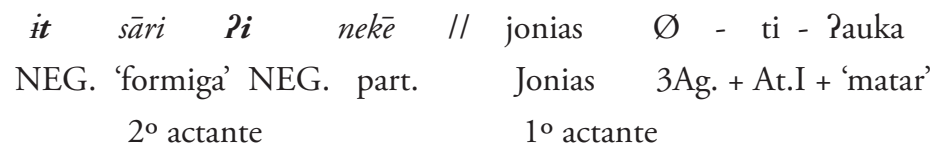

"Não foi formiga // que Jonias matou."

(25) it awai?a $2 \boldsymbol{i}$ ti ran // valmira $\varnothing-\varnothing$ - tei NEG. 'cará' NEG. part. part. Valmira 3sg.+ At. I + 'assar' $2^{\circ}$ actante $\quad 1^{\circ}$ actante

"Não foi CARÁ // que Valmira assou."

Nos exemplos anteriores, tem-se construçóes biactancias, nas quais o segundo actante é o termo negado e focalizado por meio do emprego das seguintes estratégias: posição em início de enunciado, entonação ascendente e uso dos morfemas neke em (23) e (24) e $\boldsymbol{t} \boldsymbol{i}+\boldsymbol{r a n}$ em (25). Pode-se observar que a negaçáo e focalização do segundo actante náo implica uma mudança na orientaçáo do verbo, este permanece na voz ativa, sendo essa a voz que apresenta no enunciado 'neutro' do ponto de vista enunciativohierárquico, ou seja, sem negação e sem focalização de constituinte. Vejamos agora exemplos de negação e focalização de um circunstante: 
it ukit puat $2 \boldsymbol{i}$ rapin // minka?u a - tu - ?u NEG. sal pelo NEG. Asp. 'mingau' 1sg. + At.I +'comer' "Não foi COM SAL // o mingau que eu comi."

$$
\text { it na?atpo } 2 \boldsymbol{i} \text { ti ran // korowi } \varnothing-\text { tu - Pu sahai }{ }^{14}
$$
NEG. 'ontem' NEG. part. part. 'Korowi' 3Ag.+At. I +'comer' 'saúva' "Não foi ONTEM // que Korowi comeu saúva."

Em (26) e (27), tem-se construçóes biactancias, nas quais os termos que assumem a função de circunstante são negados e focalizados. As estratégias usadas para focalizar o circunstante nesses enunciados foram o deslocamento da posiçáo canônica pós-verbal para a posição focal de início de enunciado, aliada a uma entonação ascendente, em (26), sendo que, em (27), houve também o emprego da partícula enfática $\boldsymbol{t} \boldsymbol{i}$ e da partícula enunciativa ran após o circunstante negado.

\section{Consideraçóes finais}

Pode-se observar que, em Sateré-Mawé, a focalização de constituintes, tanto em enunciados afirmativos quanto em negativos, ocorre mediante o emprego de uma das estratégias apresentadas por Creissels $(2006 ; 2010)$ e já observada em outras línguas do mundo, ou seja, a combinação da entonação e ordem das palavras elou adição de formas morfológicas. Em Sateré-Mawé, o constituinte focalizado ocupa sempre a posiçáo inicial ou pré-verbal do enunciado e apresenta uma entonação ascendente, podendo ou não ser seguido de partículas enfáticas indicadoras de foco (neke ou $\boldsymbol{t} \boldsymbol{i}$ ).

Também foi possível verificar que a negação de constituinte implica em sua focalização, ou seja, o constituinte negado vai ocupar a posiçấo focal, que é a de início de enunciado ou pré-verbal, e apresentar uma entonação ascendente. Pode-se concluir, então, que a negação de constituinte é inerentemente focal em Sateré-Mawé.

\footnotetext{
${ }^{14}$ Sahai, conhecida em Português também como 'saubataia' é uma espécie de formiga, comida típica dos Sateré-Mawé.
} 


\section{Referências}

CREISSELS, Denis. Syntaxe générale une introduction typologique 2. Paris: Lavoisier, 2006.

Negation et focus preverbal. CNRS Editions, 2010, p. 81-100. Disponível em: < http://www.deniscreissels.fr/public/Creissels-neg.foc.prev. pdf >. Acesso em: jan. 2011.

HAGEGE, Claude. La structure des langues. Paris: 1982.

ILARI, Rodolfo. Perspectiva funcional da frase portuguesa. Campinas: Editora da UNICAMP, 1992.

LAZARD, Gilbert. L'actance. Paris: Presses Universitaires de France, 1994.

RODRIGUES, Aryon D. Línguas brasileiras: Para o conhecimento das Línguas Indígenas. São Paulo: Loyola, 2002.

TOURATIER, Christian. La négation: essai de définition et portée. In: TOURATIER, C.; ZAREMBA, C. (Org.). La négation. Aix-en-Provence (França): Publications de L'Université de Provence, 2007.

Negação e focalização em Sateré-Mawé

Dulce Franceschini Denize de Souza Carneiro Recebido em 22/07/2015 Aprovado em 25/09/2015 